\title{
Técnica minimamente invasiva para restabelecimento de dimensão vertical de oclusão de dentição com erosão
}

\author{
Minimally invasive technique to restore the vertical \\ dimension of occlusion of a dentition with erosion
}

\begin{abstract}
RESUMO
Introdução: A erosão dentária caracteriza-se como uma condição multifatorial associada com a perda irreversível de estrutura dentária resultante de processo químico envolvendo fontes ácidas não bacterianas. Nos casos mais severos o grau de dano tecidual pode não raro provocar a redução da dimensão vertical de oclusão. O amplo desenvolvimento das técnicas adesivas tem favorecido a adoção de procedimentos mais conservadores com preservação de estrutura dentária hígida. Objetivo: Relatar um caso clínico de técnica aditiva minimamente invasiva para reanatomização de dentes anteriores superiores como parte integrante do restabelecimento de dimensão vertical de oclusão (DVO) de arcadas danificadas pelo processo de erosão dentária. Relato do Caso: Paciente HGH, 42 anos, gênero feminino, apresentou com queixa de insatisfação com a aparência estética de seu sorriso. As imagens de face apresentam sinais característicos de uma dimensão vertical de oclusão reduzida, associada a desgaste generalizado dos dentes anteriores. Para a reanatomização da face palatal dos dentes 11,12,13, 22 e 23, bastante destruída, optou-se pela técnica aditiva de com resina composta direta associada à faceta cerâmica nas faces vestibular e incisal, conhecida como Técnica de Sanduíche. O emprego de uma matriz de silicone transparente possibilitou uma reprodução fiel, e tecnicamente mais simplificada, da anatomia palatal definida no enceramento. Conclusão: A técnica Sanduiche apresenta-se como alternativa segura, exequível e efetiva para o restabelecimento de DVO de arcadas severamente danificadas pelo processo de erosão dentária.
\end{abstract}

Palavras-chave: Erosão dentária; Dimensão vertical de oclusão; Adesão dentária.

\section{ABSTRACT}

Introduction: Dental erosion is characterized as a multifactorial condition associated with the irreversible loss of tooth structure resulting from a chemical process involving non-bacterial acid sources. In the most severe cases, the degree of tissue damage can often cause a reduction in the vertical dimension of occlusion (VDO). The broad development of adhesive techniques has favored the adoption of more conservative procedures with the preservation of a healthy dental structure. Objective: To report a clinical case of a minimally invasive additive technique for re-anatomization of upper anterior teeth as part of the restoration of the vertical dimension of occlusion of damaged arches by the process of dental erosion. Case report: Patient HGH, 42 years old, female, complained of dissatisfaction with the aesthetic appearance of her smile. The face images show characteristic signs of a reduced vertical dimension of occlusion, associated with generalized wear of the anterior teeth. For the re-anatomization of the palatal face of the teeth 11,12,13, 22 and 23, which was quite destroyed, we opted for the additive technique with direct composite resin associated with the ceramic facet on the buccal and incisal faces, known as the Sandwich Technique. The use of a transparent silicone matrix allowed a faithful and technically simplified reproduction of the palatal anatomy defined in the waxing. Conclusion: The Sandwich technique presents itself as a safe, feasible and effective alternative for the restoration of VDO of arches severely damaged by the process of dental erosion.

Keywords: Tooth erosion; Vertical dimension of occlusion; Dental adhesion.
Alfeu da Veiga Jardim Neto ${ }^{1}$

Jorge Luiz de Oliveira Cruvinel Filho

Paulo Thiago Evangelista da Silva ${ }^{3}$

Kássio Lopes Costa ${ }^{4}$

Julie Marra de Paula ${ }^{5}$

Sicknan Soares da Rocha ${ }^{6}$

${ }^{1}$ Especialista em Ortodontia e Prótese Dentária pela Associação Brasileira de Odontologia, Goiás.

${ }^{2}$ Especialista em Prótese Dentária pela

Associação Brasileira de Odontologia/Goiás.

Mestrando em Ciências da Saúde pela Uni-

versidade Federal de Goiás. Prof. Titular do

curso de Odontologia do Centro Universitário UniGoyazes.

${ }^{3}$ Especialista em Prótese Dentária pela Associação Brasileira de Odontologia, Goiás.

${ }^{4}$ Especialista em Prótese Dentária pela Associação Brasileira de Odontologia/Goiás. Especialista em Implantodontia pela UNESP/Araraquara. Mestre em Prótese Dentária pela SLMandic/ Campinas.

${ }^{5}$ Mestre e Doutora em Reabilitação Oral pela UNESP/Araraquara. Profa. Titular do curso de Odontologia da Universidade Paulista - Campus Flamboyant.

${ }^{6}$ Mestre e Doutor em Reabilitação Oral pela UNESP/Araraquara. Prof. Associado da Faculdade de Odontologia da Universidade Federal de Goiás.

Submetido em: 13-3-2021

Aceito em: 24-6-2021 


\section{INTRODUÇÃO}

O restabelecimento da anatomia de dentes com lesões não cariosas pode representar um grande desafio, sobretudo quando a perda de estrutura dentária está associada à redução da dimensão vertical de oclusão (DVO). O sucesso no tratamento desses casos inicia-se pelo correto entendimento e identificação dos fatores causais, que invariavelmente são múltiplos.

A abordagem diagnóstica deve ser ampla para que proporcione um amparo sólido na determinação de um plano de tratamento consistente, seguro e com resultados previsíveis e duráveis a longo prazo.

A erosão dentária mais recentemente tem sido considerada uma condição multifatorial associada com a perda irreversível de estrutura dentária resultante de processo químico envolvendo fontes ácidas não bacterianas. ${ }^{1}$ Alimentos e bebidas ácidas como frutas cítricas, medicamentos, refluxo gastroesofágico e desordens alimentares são fatores desmineralizantes que contribuem para uma alta incidência de lesões não cariosas e erosão dental. ${ }^{2,3}$ Num estágio severo pode provocar danos consideráveis, principalmente nos dentes anteriores superiores. ${ }^{4}$ Nestes casos, não raro há um comprometimento da dimensão vertical de oclusal, levando à sua redução.

Nos casos de perda severa de estrutura dentária o aumento de DVO apresenta as vantagens de prover espaço para o material restaurador, melhorar a exposição estética do dente, retificar o relacionamento dos dentes anteriores, permitir o restabelecimento da oclusão fisiológica e minimizar a necessidade de procedimento clínicos biologicamente invasivos como cirurgias de aumento de coroa clínica e tratamento endodôntico eletivo. ${ }^{5-8}$

O procedimento de restabelecimento de DVO de pacientes dentados envolve certa complexidade e tradicionalmente fora executado empregando restaurações do tipo coroa total em quase todos os dentes, cuja agressividade do desgaste de estrutura dentária, pode levar a tratamento endodônticos, sobretudo em pacientes jovens. ${ }^{9-11}$

Com o importante desenvolvimento das técnicas e sistemas adesivos, tornou-se possível a adoção de procedimentos menos invasivos, permitindo a preservação máxima da estrutura dentária remanescente. De maneira genérica são denominadas técnicas minimamente invasivas, sendo normalmente representadas pelo emprego de onlays nos dentes posteriores e facetas cerâmicas nos dentes anteriores. ${ }^{4}$

Nos dentes anteriores as lesões de erosão severa comprometem grandemente a face palatal, requerendo sua reanatomização como forma de restabelecer a harmonia dos movimentos excursivos mandibulares. Para tanto são ainda frequentemente utilizadas as restaurações do tipo coroa total, haja vista que as restaurações parciais como as facetas envolvem somente as faces vestibular e incisal. Caracteristicamente os preparos de coroa total são muito agressivos, uma vez que independentemente da higidez da estrutura remanescente, deve envolver as faces proximais e possibilitar a criação de um eixo de inserção axial e único.

Alternativamente, procurando aplicar os preceitos da odontologia minimamente invasiva, tem sido propostas interessantes técnicas adesivas norteadas pela máxima preservação de estrutura dentária. Nesse contexto, pode ser destacada a técnica Sanduiche, descrita por Vailitu e Belser, ${ }^{4,12,13}$ cuja particularidade envolve nos dentes anteriores a combinação de duas restaurações, onlay palatal de resina e faceta cerâmica vestibular/incisal. 
O objetivo deste trabalho é relatar um caso clínico de restabelecimento de dimensão vertical de oclusal em que foi empregada a técnica de Sanduiche para a reanatomização dos dentes anteriores superiores severamente danificados pelo processo de erosão dentária.

\section{RELATO DO CASO}

Paciente HGH, 42 anos, gênero feminino, apresentou com queixa de insatisfação com a aparência estética de seu sorriso. Como parte integrante do protocolo de atendimento, após a anamnese foi realizado o protocolo fotográfico com finalidade de diagnóstico e elaboração de plano de tratamento. As imagens de face apresentam sinais característicos de uma dimensão vertical de oclusão reduzida. (Figuras 1-3) Ao exame intraoral comprova-se um desgaste generalizado dos dentes anteriores resultando numa relação de oclusão desfavorável, com overbite acentuado, e várias necessidades odontológicas. (Figuras 4-6)
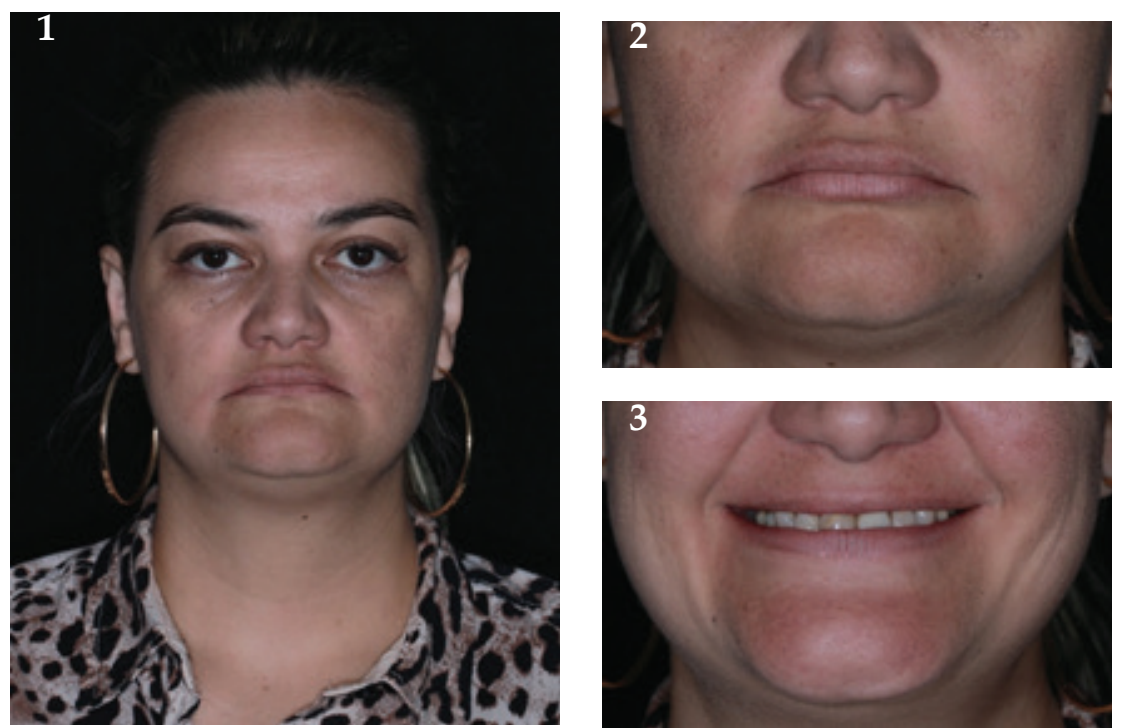

Figuras 1 a 3: Imagens de face com características de DVO reduzida

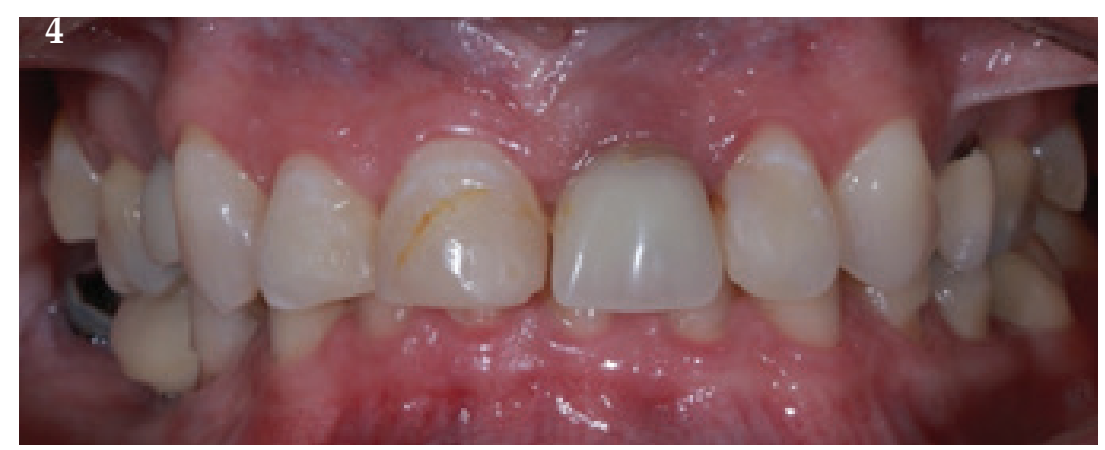

Figura 4: Relação de oclusão com overbite acentuado 

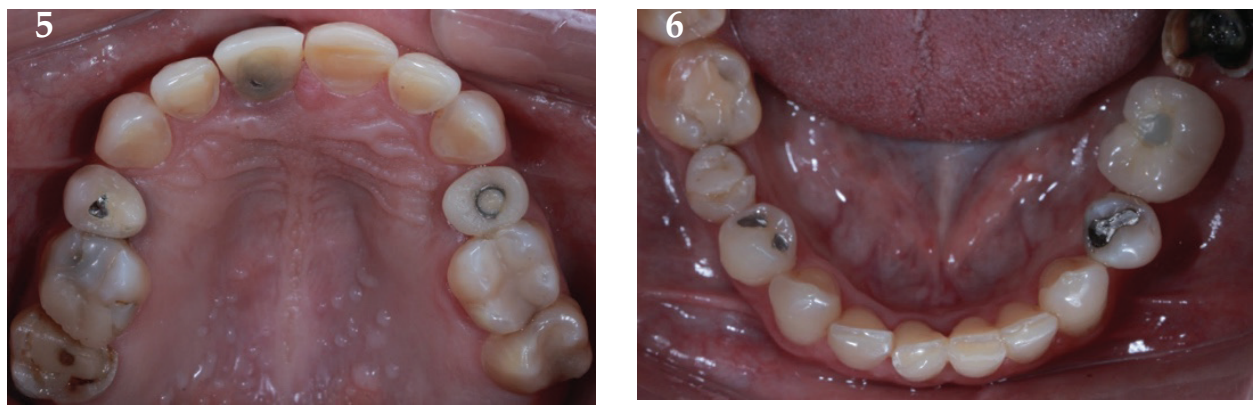

Figuras 5 e 6: Faces palatais dos anteriores superiores e incisais dos inferiores com acentuada perda de estrutura.

Na investigação dos fatores etiológicos, o processo de erosão foi fortemente relacionado à extensa perda de estrutura dentária na palatal dos dentes anteriores superiores. Adicionalmente, estava associada uma parafunção mastigatória. Estes dois principais fatores etiológicos foram confirmados pelos hábitos de alimentação ácida e ranger dos dentes, relatados pela paciente.

O plano de tratamento envolveu inicialmente orientações à paciente quanto ao controle dos hábitos deletérios identificados. No contexto da reabilitação oral, de relativa complexidade, houve definição pelo restabelecimento da DVO, incluindo restaurações inlays, onlays, facetas, coroas sobre dentes e implantes.

A partir das imagens da face, incluindo lábio em repouso e sorriso, e referenciais das dimensões dos incisivos centrais superiores, foi realizado o planejamento digital do sorriso para definição do "tamanho ideal" dos dentes anteriores superiores. (Figuras 7 e 8) Considerando a necessidade de definição de uma nova DVO, estes referenciais estéticos precisam estar em sintonia com os aspectos funcionais. Para tanto, os modelos de gesso são montados no articulador semi-ajustável (ASA), necessitando da confecção do Jig de Lucia para o registro interoclusal.
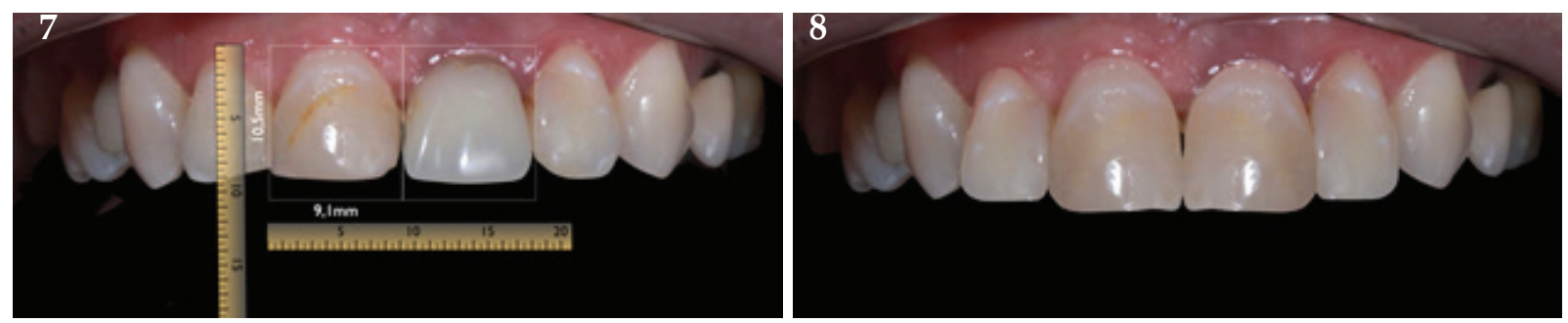

Figuras 7 e 8: Planejamento digital com definição das dimensões dos incisivos superiores.

O registro da relação maxilomandibular foi realizado na posição de máxima intercuspidação (MI), uma vez que o uso da relação cêntrica (RC) iria aumentar o overjet da paciente, que já era acentuado pelo posicionamento retruído da mandíbula em relação à maxila. A quantidade do aumento da DVO foi definida como o suficiente para criar espaço vertical para a satisfatória reanatomização dos dentes desgastados. Com os modelos montados em ASA na nova DVO e o planejamento digital, foi realizado o enceramento dos dentes, com adequado restabelecimento das curvas de Spee e Wilson e integração dos referenciais estéticos e funcionais. (Figuras 9-12) 

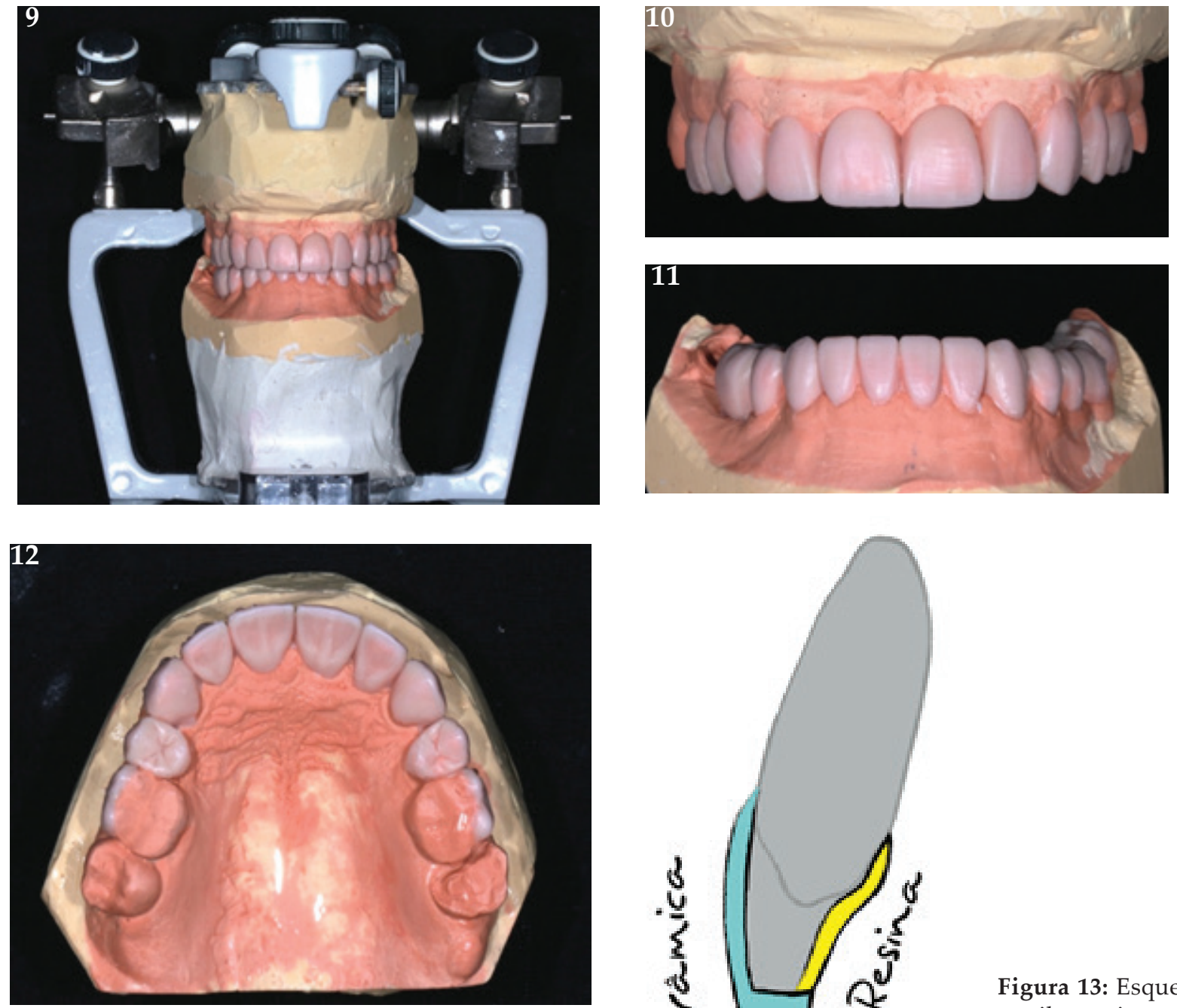

Figuras 9 a 12: Modelos encerados.

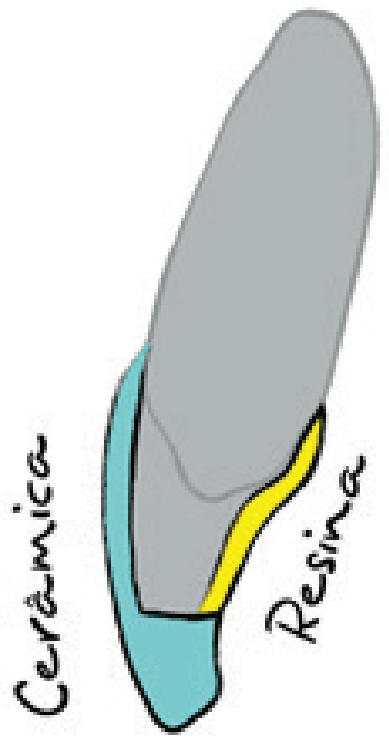

Figura 13: Esquema ilustrativo da Técnica de Sanduíche.

Considerando a necessidade de reanatomização da face palatal dos dentes 11,12,13, 22 e 23, bastante destruída, optou-se pela técnica aditiva com resina composta direta associada à faceta cerâmica nas faces vestibular e incisal, com pequena modificação da Técnica de Sanduiche descrita por Vailati e Belser ${ }^{4,12,13}$. (Figura 13) O principal benefício foi a preservação de estrutura de esmalte para a adesão, uma vez que o uso de restauração única de coroa total exigiria um desgaste excessivo para a obtenção do eixo de inserção.

A partir do enceramento foram obtidas as matrizes de silicona (Zetalabor, Zhermack, Badia Polesine, Itália) para realização do mock-up ou ensaio restaurador com resina bis-acrílica (Structur 2, Voco, Germany). Esse procedimento permite a avaliação de ambos, profissional e paciente, quanto à previsão dos resultados estéticos e funcionais a serem alcançados com a nova DVO. (Figuras 14-16) Após a aprovação da paciente deu-se inicio à execução do plano de tratamento. 

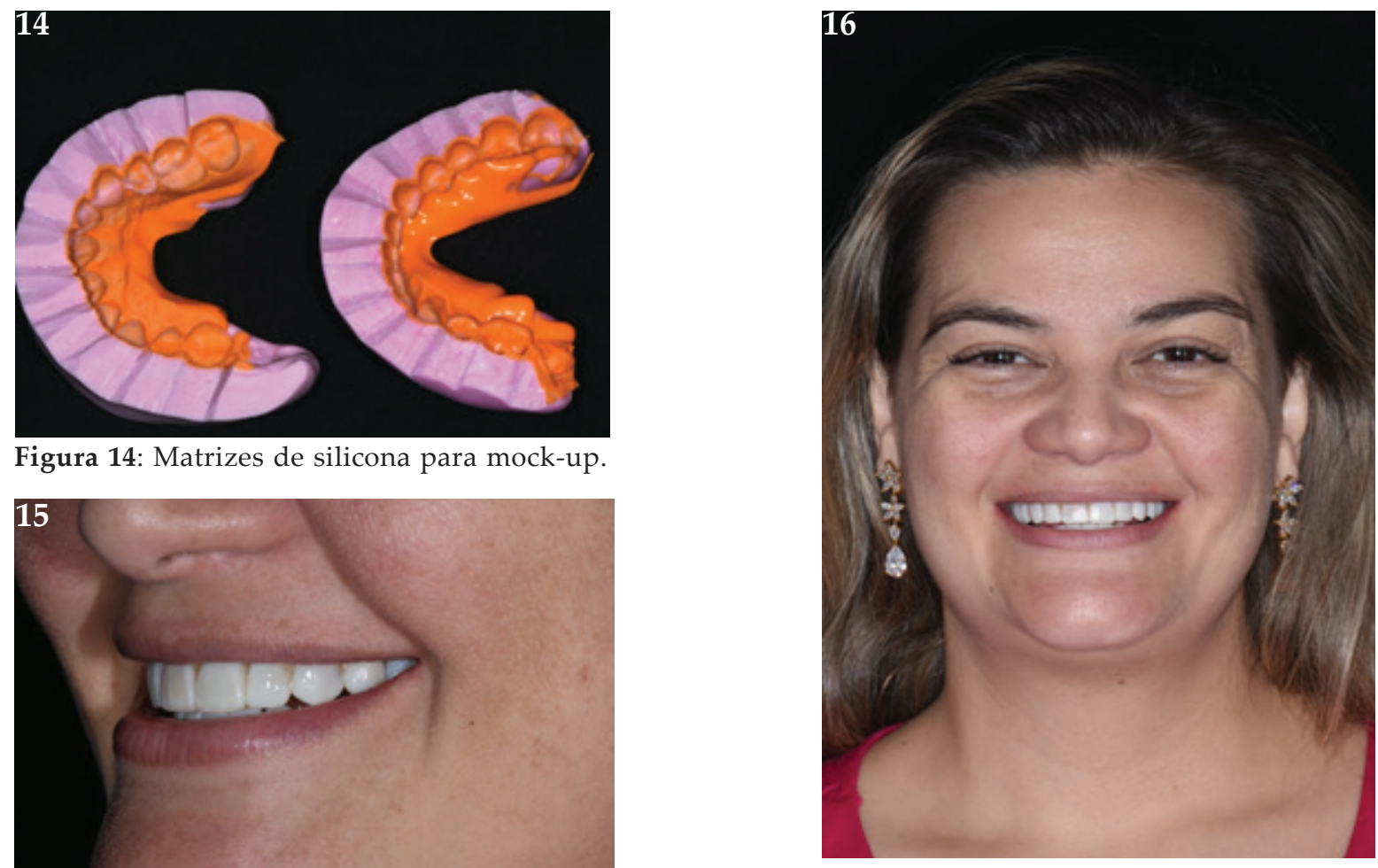

Figura 14: Matrizes de silicona para mock-up.

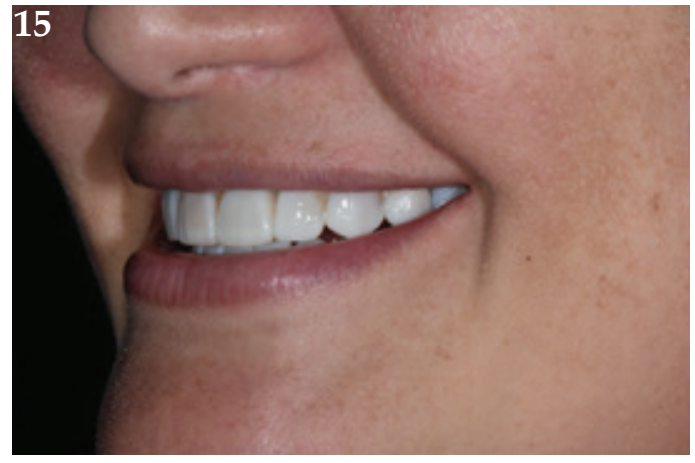

Figuras 15 e 16: Aspectos do sorriso com mock-up de resina bis-acrílica.
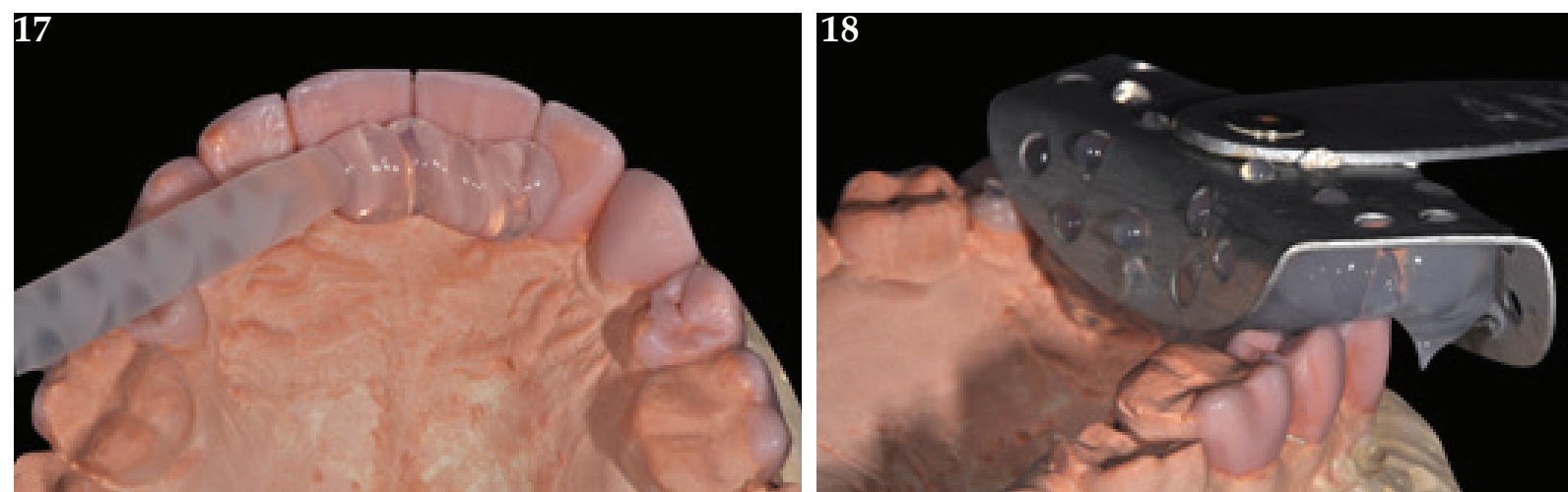

Figura 17 e 18: Pré-moldagem do modelo encerado para confecção de matriz de silicona transparente.

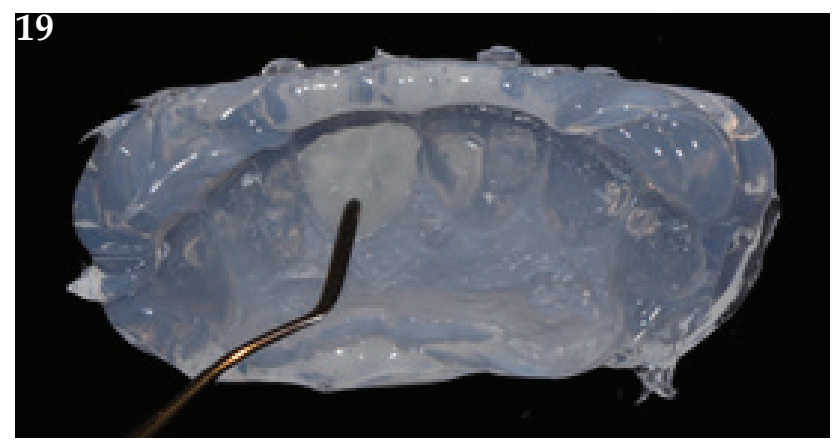

Figura 19: Insersão de resina composta na matriz de silicona.

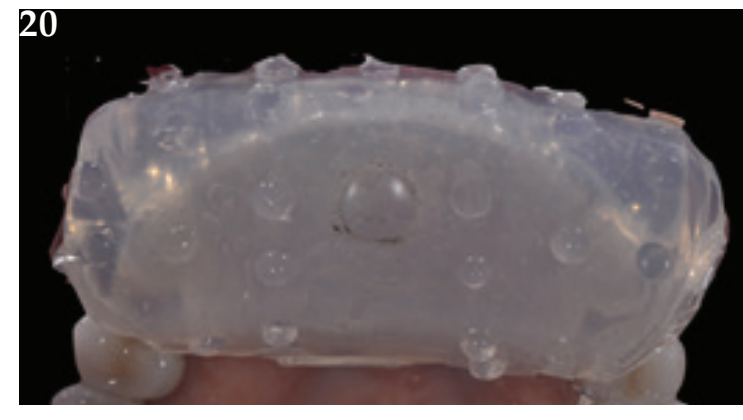

Figura 20: Posicionamento da matriz de silicona em boca. 


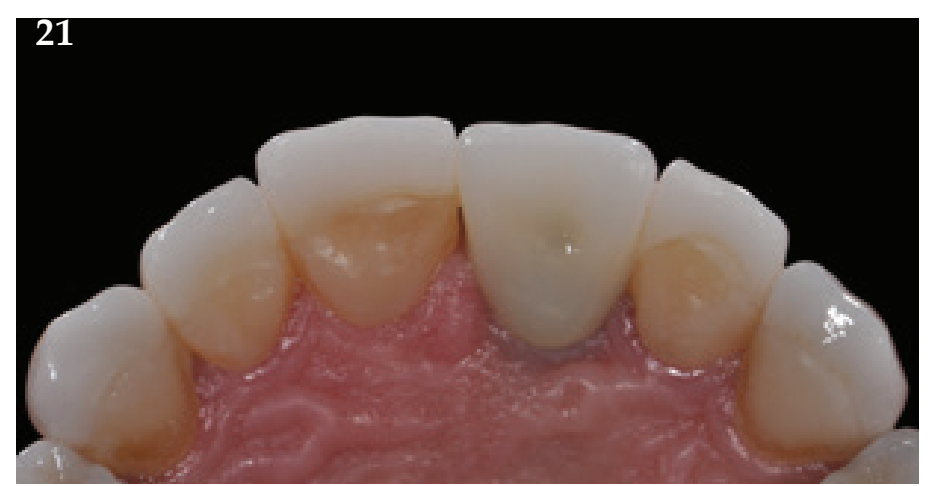

Figura 21: Aspecto das faces palatais dos dentes 11,12,13,22 e 23 após acabamento e polimento das resinas
Para a aplicação da técnica aditiva na restauração da face palatal dos dentes naturais anteriores superiores foi utilizada uma silicona de adição transparente (Elite Transparente, Zhermack, Badia Polesine, Itália) por permitir a passagem de luz e fotopolimerização da resina composta. Empregando uma moldeira parcial foi realizada uma pré-moldagem do modelo encerado para confecção de uma matriz de silicona transparente e facilitar a reprodução da anatomia funcional dos referidos dentes. Após o preparo da superfície dentária para a adesão, condicionamento total com ácido fosfórico (Ultra-etch, Ultradent, Indaiatuba, Brasil), primer e adesivo (Optibond FL, Kerr, São Paulo, Brasil), a resina composta (Forma, Ultradent, Indaiatuba, Brasil) foi inserida e em seguida o molde é posicionado em boca para a fotopolimerização (Valo, Ultradent, Indaiatuba, Brasil). O molde foi removido e complementada a fotopolimerização, seguida de acabamento e polimento. (Figuras 17-21)

Dentro do protocolo de tratamento, nessa mesma sessão clínica a DVO foi restabelecida de caráter temporário empregando as matrizes para mock-up e cimentação adesiva das restaurações de resina bis-acrílica (Structur 2, Voco, Germany). (Figuras 22 e 23) Após o período de 30 dias, providencialmente aguardado para adaptação e avaliação da nova DVO, optou-se pela finalização da arcada superior mantendo a inferior com as restaurações transitórias. Os preparos foram orientados pelas restaurações transitórias, técnica da avaliação estética temporária, que favorece a minimização do desgaste dentário. (Figuras 24 e 25)
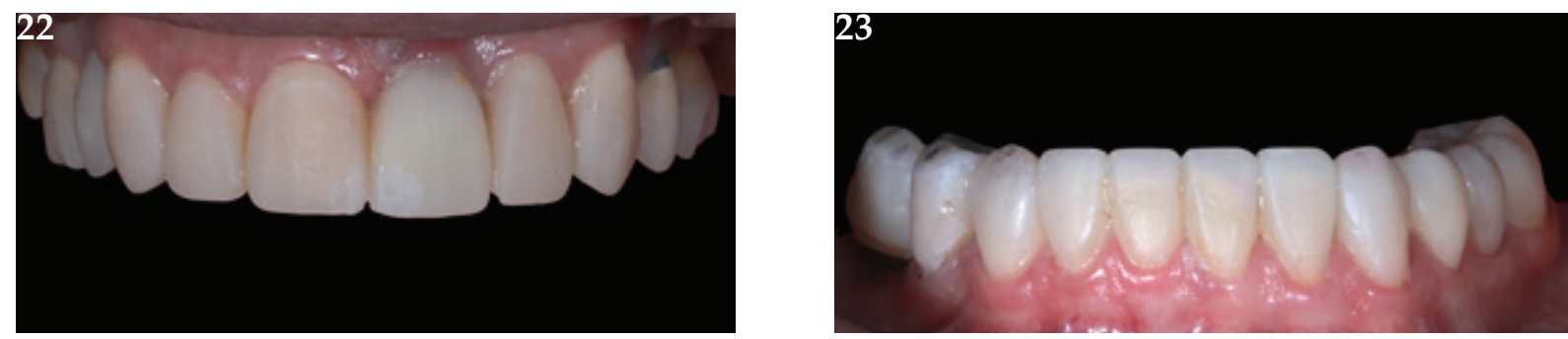

Figuras 22 e 23: Restaurações transitórias de resina bis-acrílica cimentadas para o restabelecimento imediato da DVO.
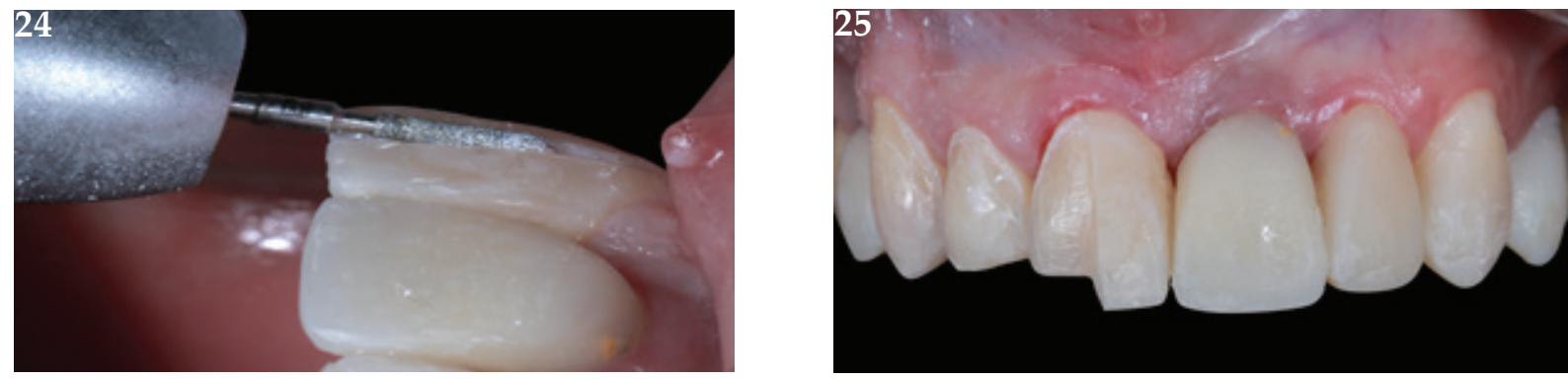

Figura 24 e 25: Preparos dentários orientados pelo mock-up com evidências de mínimo desgaste. 
Em seguida ao polimento dos preparos foi realizada moldagem com silicona de adição (Variotime, Kulzer South America, São Paulo, Brasil), empregando a técnica do reembasamento com duplos fios (Ultrapak, Ultradent, Indaiatuba, Brasil). Para as restaurações transitórias novamente foi utilizada a matriz do mock-up e resina bis-acrílica (Structur 2, Voco $\mathrm{GmbH}$, Germany). As restaurações cerâmicas de dissilicato de lítio (E-Max, Ivoclar Vivadent, Barueri, Brasil), incluindo onlays, facetas, vonlays e coroas dento e implantossuportadas, foram confeccionadas utilizando a tecnologia CAD/CAM. (Figuras 26 e 27) Para a cimentação final foi utilizada a técnica adesiva com cimento fotopolimerizável (Variolink Esthetic, Ivoclar Vivadent, Barueri, Brasil). Finalizada a arcada superior, os procedimentos de preparos, moldagem, restaurações transitórias, ajustes e cimentação foram repetidos na arcada inferior.
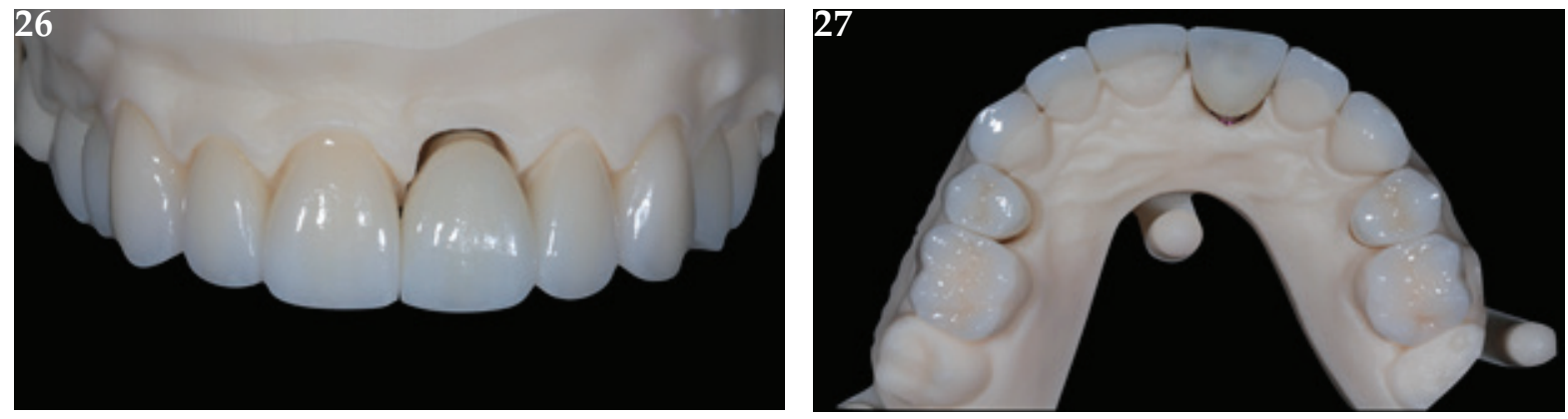

Figuras 26 e 27: Restaurações de dissilicato de lítio no modelo obtido por impressão 3D.

As figuras 28 a 30 ilustram o aspecto intraoral das novas restaurações que resultaram na nova DVO. Além de favorecer um novo relacionamento entre as arcadas dentárias restabelecendo adequadamente as funções do sistema estomatognático, a reabilitação conseguiu atender de maneira bastante satisfatória às expectativas da paciente que não se apresentava feliz com a sua condição odontológica inicial. (Figuras 31-33)
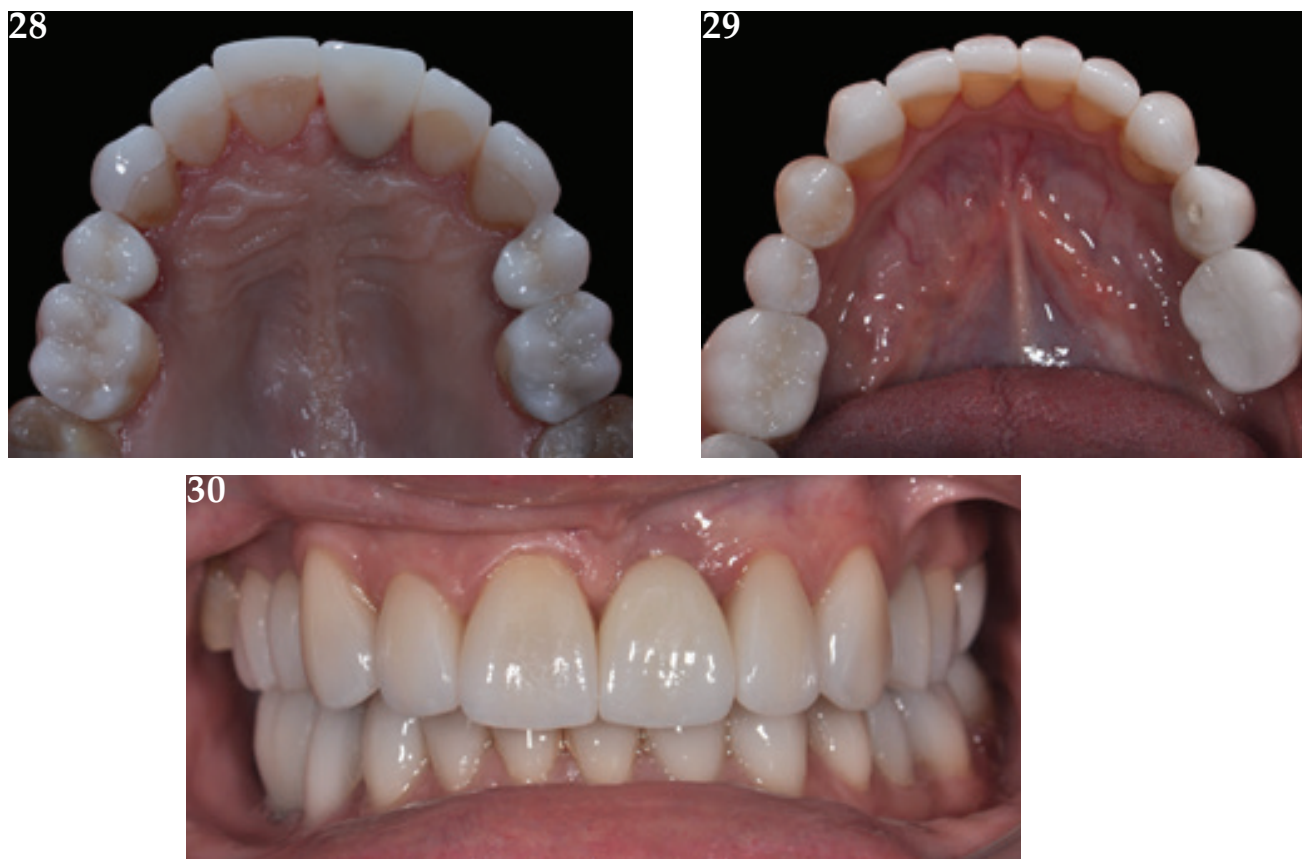

Figuras 28 a 30: Aspecto intraoral das restaurações finais com restabelecimento da DVO. 

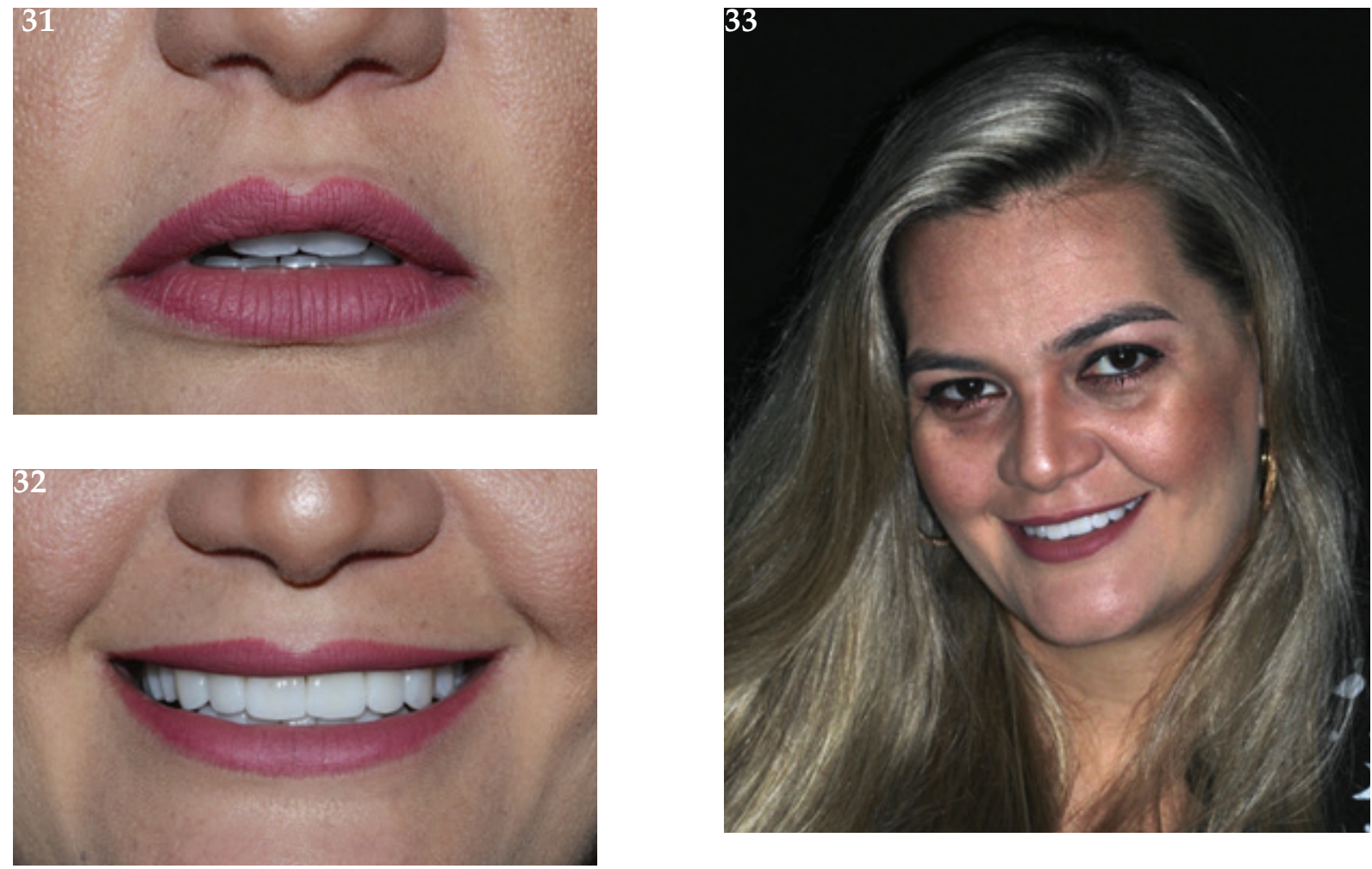

Figuras 31 a 33: Aspecto facial evidenciando o resultado estético bastante favorável e satisfação da paciente.

\section{DISCUSSÃO}

A erosão dentária representa na atualidade uma questão de saúde, que ainda que de maneira sutil, tem aumentado e despertado a atenção. O estudo epidemiológico de Bartlett et al., ${ }^{14}$ mostrou que 30\% de adultos jovens, 18 a 35 anos, apresentaram pelo menos um dente com perda de estrutura dentária por erosão. O processo de destruição dentária é cumulativo e pode levar a considerável desgaste da superfície dentária.

Atuando de maneira não isolada, o processo erosivo geralmente está combinado com processos mecânicos como abrasão causada por hábitos orais e substâncias abrasivas, incluindo os dentrifícios, ou atrição causada pelo contato dente a dente. ${ }^{15}$ Essa combinação de múltiplos fatores, representados pela erosão, abrasão e atrição tem contribuído para a prematura perda excessiva de estrutura dentária, sobretudo em pacientes jovens.

Quando esses fatores não são identificados e controlados numa fase inicial não raro repercutem de maneira negativa na dimensão vertical de oclusão, provocando sua implacável redução. A premente necessidade de intervenção e restabelecimento da DVO em paciente dentado, coloca o profissional diante de um grande desafio, haja vista que invariavelmente o tratamento restaurador envolve a intervenção oclusal em todos os dentes presentes. Além do grau de complexidade inerente a esse tipo de reabilitação, o custo relativamente alto agregado representa outro fator limitante e que muitas vezes determina sua forma de execução.

A erosão severa caracteristicamente provoca substancial dano na face palatal dos dentes anteriores superiores, além de principalmente quando associada à atrição resultar 
também na redução de altura incisal desses dentes. Tradicionalmente o meio utilizado para a reanatomização dos dentes anteriores com tais demandas são as coroas totais. Sendo restaurações que sabidamente requerem um desgaste mais agressivo imputando a necessidade do preparo envolver todas as faces do dente, independentemente da sua condição de higidez.

A já sedimentada odontologia adesiva trouxe repercussões extremamente positivas, possibilitando a minimização do sacrifício da estrutura dentária remanescente no processo de preparo para os procedimentos reabilitadores. Nesse atual contexto das restaurações minimamente invasivas há amplo destaque para o emprego das onlays nos dentes posteriores e facetas nos dentes anteriores. ${ }^{4}$

A que se destacar, contudo, que nos casos específicos de erosões cujas faces palatais dos dentes anteriores superiores foram severamente danificadas, as facetas dentárias não seriam efetivas. Isto ocorre porque sendo uma restauração parcial, seu envolvimento fica restrito às faces vestibular e incisal, e eventualmente as proximais. Estas importantes peculiaridades têm induzido a realização nesses dentes de preparos de coroa total, cuja necessidade de obtenção de um eixo de inserção axial único requer um desgaste em maior quantidade, independentemente das condições de higidez do esmalte dentário.

A técnica de Sanduiche, descrita inicialmente por Vailati e Belser ${ }^{4,12,13}$, surgiu com a proposta de dar uma solução mais conservadora para os dentes anteriores superiores que apresentem a face palatal com severos danos provocados pelas erosões dentárias. Explorando os avanços e sobretudo a maior efetividade dos sistemas adesivos na estrutura de dentina a técnica inclui a reanatomização desses dentes por meio de duas restaurações: pré-concebida faceta cerâmica vestibular/incisal e uma adicional onlay palatal de resina. (Figura 13)

Originalmente, o restabelecimento da face palatal para devolver as guias anteriores e consequente harmonia dos movimentos mandibulares excursivos foi realizado pela técnica indireta utilizando-se de cimentação adesiva à semelhança da fixação da faceta cerâmica. No presente caso clínico optou-se pelo emprego de resina composta direta associada ao emprego de molde de silicona de adição transparente. A possibilidade de fotopolimerização da resina através da silicona nos sinalizou para a simplificação e alta previsibilidade do procedimento, uma vez que seria possível a reprodução fiel da anatomia funcional obtida no enceramento realizado no articulador semi-ajustável.

Adicionalmente, a escolha pela resina composta na técnica direta foi norteada principalmente pelas suas características favoráveis de não requerer preparos invasivos e possibilidade de confecção numa única sessão, além do evidente baixo custo. ${ }^{16} \mathrm{~A}$ eminente preocupação quanto ao comportamento clínico da técnica direta tem motivado a realização de estudos no sentido de clarear o seu entendimento. Numa revisão sistemática e meta-análise de longevidade de resina composta direta e indireta, Veiga et al. ${ }^{17}$ evidenciaram a ausência de diferença estatisticamente significante de longevidade clínica entre estas duas técnicas de uso.

A confirmação da reprodução da forma anatômica palatal e guias excursivas foi realizada pela técnica adotada na confecção das restaurações transitórias. Utilizando-se da matriz do mock-up a DVO foi instantaneamente restabelecida por meio da cimentação adesiva das restaurações de resina bis-acrílica. Todos os dentes com suas dimensões restabelecidas os eventuais ajustes foram realizados incluindo a forma das onlays palatais 
de resina.

Para a determinação da nova DVO foram utilizados critérios estéticos e funcionais. Por meio do planejamento digital do sorriso, empregando as ferramentas do programa Keynote/IOS foram definidas as dimensões dos seis dentes anteriores superiores. A partir destes com o estabelecimento da curva de Spee os dentes posteriores superiores foram restabelecidos em altura e forma anatômica. O grau de aumento da DVO, por ser um paciente dentado, foi definido buscando o espaço vertical suficiente para as restaurações, ${ }^{18}$ que incluíram coroas totais, sobre dente e implante, facetas, onlays com recobrimento vestibular/vonlays. A partir destas definições os modelos foram montados em articulador semi-ajustável para a realização do enceramento. (Figuras 9 a 12)

Ainda que a efetividade da técnica Sanduiche esteja na dependência da condição inicial muitas vezes desfavorável, incluindo falta de esmalte, dentina esclerótica e coroa clínica curta, há resultados animadores. Num estudo prospectivo de 6 anos foram acompanhadas 70 onlays palatais de resinas associadas a facetas vestibulares de porcelana feldspática. A avaliação incluiu os seguintes critérios: adaptação e integridade marginal, condição de vitalidade pulpar, sensibilidade pós-operatória, estética e falha/sucesso da restauração. Foram observados que nenhum dente teve sua vitalidade comprometida, não houve falha de nenhuma restauração e um elevado grau de satisfação global dos pacientes. Utilizando-se de análise de escala analógica visual, a satisfação centrada no paciente revelou uma alta aceitação estética e funcional de $94,6 \% .{ }^{19}$

Definiu-se como foco principal deste relato de caso o devido destaque às particularidades da técnica Sanduiche, cuja proposta norteadora é a máxima preservação da estrutura dentária dos dentes anteriores superiores já bastante sacrificados pelo processo de erosão. Porém, há que se ressaltar a necessidade da combinação, com os devidos critérios, dos vários procedimentos requeridos para o desenvolvimento e alcance dos resultados bastante satisfatórios dessa extensa reabilitação, que devolveu função, estética e sobretudo a autoestima à paciente, que se mostrou extremamente satisfeita.

Para a manutenção dos resultados a longo prazo deve haver uma abordagem de compartilhamento de responsabilidades. Além de um controle periódico e individualizado definido pelo profissional, o paciente necessita ter aderido a uma sistemática de mudança de hábitos envolvendo um efetivo controle dos fatores causais apontados quando de sua identificação no momento do diagnóstico. No contexto da erosão dentária, os fatores relacionados ao paciente incluem possível predisposição dos dentes à erosão, hábitos comportamentais, ácido estomacal, medicações, dieta suplementar e higiene oral. ${ }^{20}$

A busca incessante pelo desenvolvimento e aprimoramento técnico baseado nas evidências científicas, deve nortear o crescimento profissional. Essa conduta minimizará a ocorrência de sobretratamentos, possibilitando a devolução das funções do sistema estomatognático de maneira mais simples, segura e com o mínimo de invasibilidade.

\section{CONCLUSÃO}

A técnica Sanduiche apresenta-se como alternativa segura, simples, exequível e efetiva para o restabelecimento de DVO de arcadas severamente danificadas pelo processo 
de erosão dentária. Valendo-se dos benefícios das técnicas adesivas, possibilitou alcançar de maneira minimamente invasiva resultados previsíveis e com longevidade clínica, correspondendo às elevadas expectativas de ambos, profissional e paciente.

\section{REFERÊNCIAS}

1. Passos VF, Melo MAS, Park J, Strassler HE. Current concepts and best evidence on strategies to prevent dental erosion. Compend Contin Educ Dent. 2019;40(2):80-86.

2. Melo MA, Passos VF, Lima JP, et al. Carbohydrate-electrolyte drinks exhibit risks for human enamel surface loss. Restor Dent Endod. 2016;41(4):246-254.

3. Ranjitkar S, Smales RJ, Kaidonis JA. Oral manifestations of gastroesophageal

reflux disease. J Gastroenterol Hepatol. 2012;27(1):21-27.

4. Vailati F, Belser UC. Full-mouth adhesive rehabilitation of a severely eroded dentition: the three-step technique. Part 1. Eur J Esthet Dent 2008;3(1):30-44.

5. Rivera-Morales WC, Mohl ND. Relationship of occlusal vertical dimension to the health of the masticatory system. J Prosthet Dent 1991;65:547-553.

6. Johansson A, Omar R. Identification and management of tooth wear. Int J Prosthodont 1994;7:506-516.

7. Keough B. Occlusion-based treatment planning for complex dental restorations: Part 1. Int J Periodontics Restorative Dent 2003;23:237-247.

8. Johansson A, Johansson AK, Omar R, Carlsson GE. Rehabilitation of the worn dentition. J Oral Rehabil 2008;35:548-566.

9. Bonilla ED, Luna O. Oral rehabilitation of a bulimic patient: a case report. Quintessence Int 2001;32:469-475. 10. Van Roekel NB. Gastroesophageal reflux disease, tooth erosion, and prosthodontic rehabilitation: A clinical report. J Prosthodont 2003;12:255-259.

11. Kavoura V, Kourtis SG, Zoidis P, Andritsakis DP, Doukoudakis A. Full-mouth rehabilitation of a patient with bulimia nervosa. A case report. Quintessence Int

2005;36:501-510.

12. Vailati F, Belser UC. Full-mouth adhesive rehabilitation of a severely eroded dentition: the three-step technique. Part 2. Eur J Esthet Dent 2008;3(2):128-46.

13. Vailati F, Belser UC. Full-mouth adhesive rehabilitation of a severely eroded dentition: the three-step technique. Part 3. Eur J Esthet Dent 2008;3(3):236-257.

14. Bartlett DW, Lussi A, West NX, et al. Prevalence of tooth wear on buccal and lingual surfaces and possible risk factors in young European Adults. J Dent. 2013;41(11):1007-1013.

15. Bishop K, Kelleher M, Briggs P, Joshi R. Wear now? An update on the etiology of tooth wear. Quintessence Int. 1997;28(5):305-313.

16. Magne P. Conservative restoration of compromised posterior teeth with direct composites: a 7-year report. Pract Periodontics Aesthet Dent 2000;12:747-749.

17. Veiga AMA, Cunha AC, Ferreira DMTP, Fidalgo TKS, Chianca TK, Reis KR, Maia LC. Longevity of direct and indirect resin composite restorations in permanent posterior teeth: A systematic review and meta-analysis. J Dent 2016;54:1-12.

18. Abdou J. Safety of increasing vertical dimension of occlusion: A systematic review. Quintessence Int 2012;43:369-380

19. Vailati F, Gruetter L, Belser UC. Adhesively restored anteriormaxillary dentitions affected by severe erosion: up to 6-year results of a prospective clinical study. Eur J Esthet Dent 2013;8(4):506-30.

20. Carvalho TS, Colon P, Ganss C, et al. Consensus Report of the European Federation of Conservative Dentistry: erosive tooth wear diagnosis and management. Swiss Dent J. 2016;126(4):342-346. 